\title{
Three-dimensional finite element analysis of fracture behaviour of adhesively bonded single lap-joints
}

\author{
A. Djebli*, A. Benhamena*, L. Aminallah*, A. Aid*, M. Benguediab**, A. Amrouche*** \\ *Laboratory LPQ3M BP 305, University of Mascara, Algeria. E-mail: ali_benhamena@yahoo.fr \\ **Department of Mechanical Engineering, University of Sidi Bel Abbes, Algeria \\ ***Laboratory LGCgE, EA 4515, faculté des sciences appliquées FSA Béthune, France
}

cross $^{\text {ref }}$ http://dx.doi.org/10.5755/j01.mech.22.5.12879

\section{Introduction}

The most common joining method is the mechanical joint, such as bolted, welded or riveted joints in various applications. These structures are subjected to complex loads taking into account their geometrical configuration and the multiplicity of the loading conditions in service. The origin of failure of these mechanical components is directly related to the presence of defects during the phase of assembled and the problem could be worsened for cyclic loading, where there is a risk of initiation and crack growth. One of the principal failures of bolted assemblies under fatigue is the fretting according to Benhamena et al $[1,2]$. The fretting phenomenon can be ignored in bonded joints, so the adhesively bonded joints have many advantages such as load distribution over larger area due to absence of holes, no damage at the interface by fretting due to the sliding in service and no stress concentrations due to the presence of holes. The fracture prediction and the reliability of such bonded joints in various practical applications are primordial given their impact on the economic plan and security. Several authors [3-7] have been studied bonded joints problems by means of experimentation and numerical simulation in order to assess the mechanical integrity of bonded assemblies, taking into account geometrical different under various loading condition. In the same context, a thorough examination of this subject can be found in Refs. [8-11]. On the other hand, single lap joint is one of the most commonly used bonding configurations. Due to its combined characteristics of simplicity and efficiency, the single-lap joint has been adopted as a standard mechanical test method for determining the shear strength (ASTM D1002-72). In addition, it has also gained the attention of aircraft, naval, wind turbine, defense applications and automobile industries. However, it is known, that during the phase of assembled of single lap joint, numerous local defects and inclusions are produced. In service, the combination of these factors under loading condition (the single lap joint configuration causes secondary bending to occur under tensile loading due to the eccentric load path inherent in the joint geometry, concentration of peel and shear stresses in the adhesive layer due to singular points, etc.) and the environmental effect (temperature, time, etc.) tends to reduce significantly the lifetime of these components. The integrity assessment of single lap joint involves a nonlinear analysis. Finite element analysis (FEA) is an important tool to design a practical mechanical component, such as bonded assembly. In this paper, the 3DFEM based on the analysis of local stress (peel and shear stresses) along the overlap area is examined. The effects of the loading magnitude and the overlap length on the distribution of peel and shear stresses were highlighted.

\section{Configuration and properties of adhesively bonded single-lap joint}

The adhesively bonded single lap joint studied in the present work is shown in Fig. 1. The two adherends used were aluminum alloy plates (AA2024-T3 aluminum alloy). The following values were selected for this work: plate thickness $e_{p}=2 \mathrm{~mm}$, adhesive thickness $e_{a}=0.2 \mathrm{~mm}$, overlap length $O L=25 \mathrm{~mm}$, the length and width of plate $L=75 \mathrm{~mm}$ and $W=25 \mathrm{~mm}$, respectively. Nonlinear behavior of the geometry and materials properties for the bonded single lap joint was considered in this paper. The stressstrain curves of the aluminium alloy 2024-T3 and the adhesive Hysol ${ }^{\circledR}$ EA9394 are presented respectively in Figs. 2 and 3 [12]. The plate is subjected to a remote uniaxial tensile load of $\sigma=60 \mathrm{MPa}$.

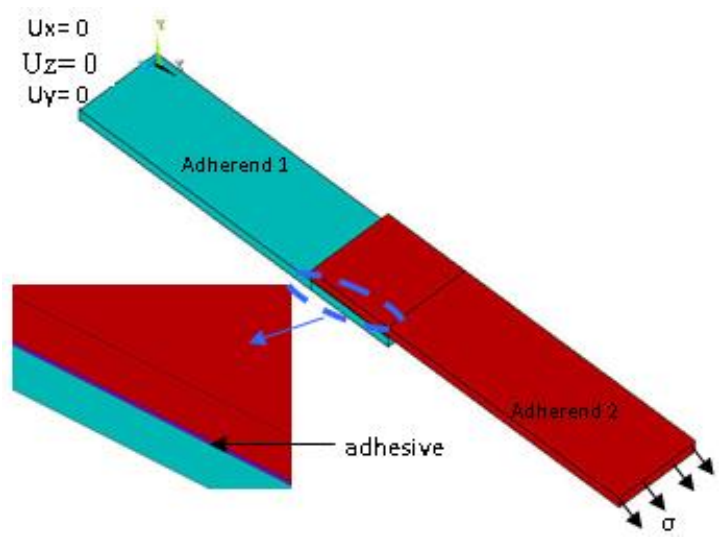

Fig. 1 Three dimensional single lap joint configuration

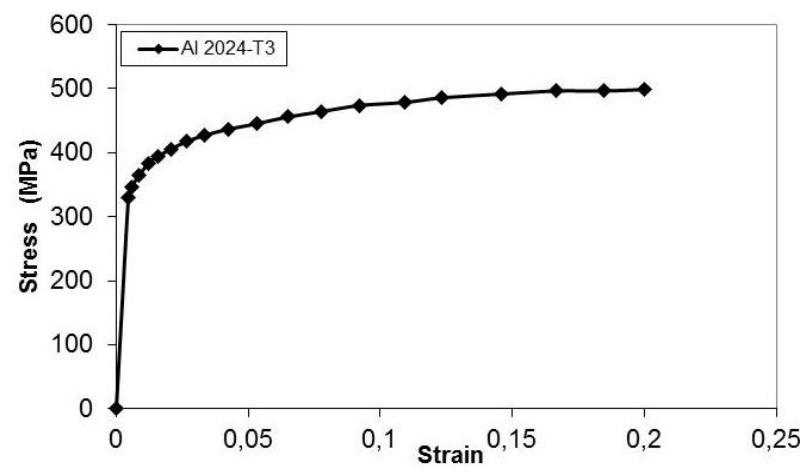

Fig. 2 Uniaxial stress-strain curve for aluminium 2024-T3 


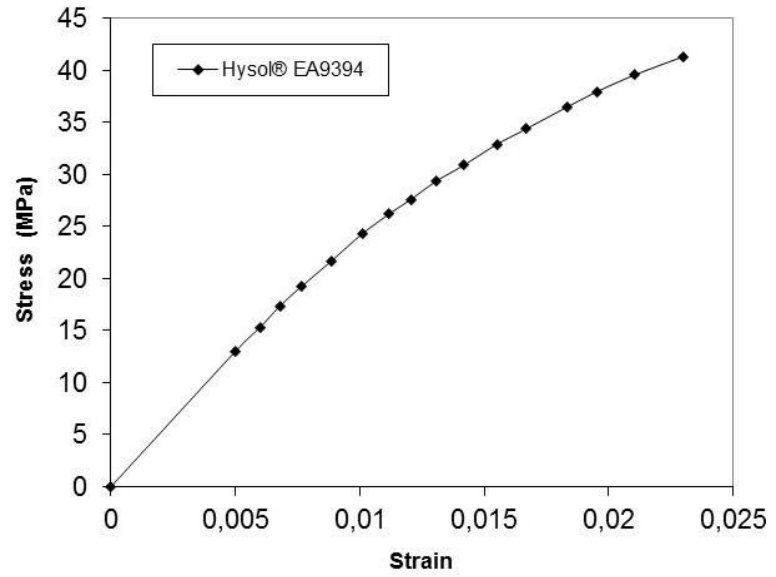

Fig. 3 Stress-strain curve for adhesive Hysol ${ }^{\circledR}$ EA9394 [12]

\section{Finite element modelling}

Finite element analysis (FEA) is an important tool to design practical mechanical joints, such as the bonded assemblies. According to the dimensions of the structure, a three dimensional model was generated using the commercial software ANSYS ${ }^{\circledR}$ (ANSYS 11, [13]) in order to determine and to perform the analyses of shear and peel stresses at the interface. A three-dimensional brick element (SOLID45) is used for modelling of bonded assembly, this element is defined by eight nodes and each having three degrees of freedom. The numerical simulation of bonded assembly in three-dimensional is known delicate for reasons related to the mesh at the interface between adhesive and adherend plats, especially when dealing an elastic-plastic material of adhesive and the substrates. The theory of incremental plasticity is introduced to model the material nonlinearity. Globally, FE model contains 80,000 elements and 88,191 nodes. The iterative method of Newton-Raphson is used as an approach to solve nonlinear equations by finite elements.

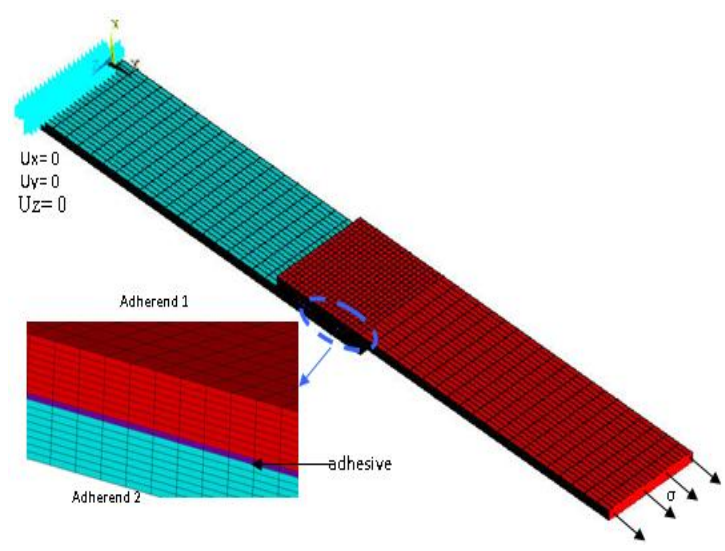

Fig. 4 Finite element mesh of bonded assembly and detail of the mesh used in the overlap length

\section{Results and discussions}

\subsection{Validation of the finite element model}

In this study, the peel and shear stresses were analysed along the overlap area in the adhesive by three finite element methods (3D-FEM). Fig. 5 present the contour of the Von-Mises stress levels at the adhesive only. The higher stress gradients are located at the vicinity of the free ends of the adhesive layer. We notice in this case that the maximum of stress is strongly concentrated at the interface between the adhesive and substrate at the free extremities of single lap joint. This phenomenon can be explained by the fact, a good adherence in the middle of overlap area and the risk of disband (crack growth) is located in the free edge of bonded assembly. A similar stress distribution was observed in the overlap area for other loading condition (i.e. a high stresses located at the free ends of the adhesive layer). This behaviour is in agreement with the experimental observations of Cheuk et al. [14].

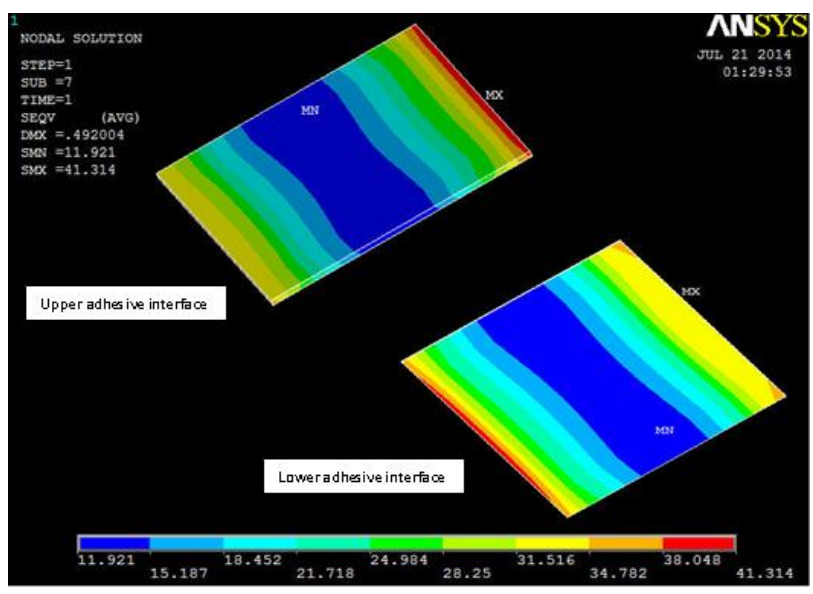

Fig. 5 Von-Mises stress distribution in the adhesive

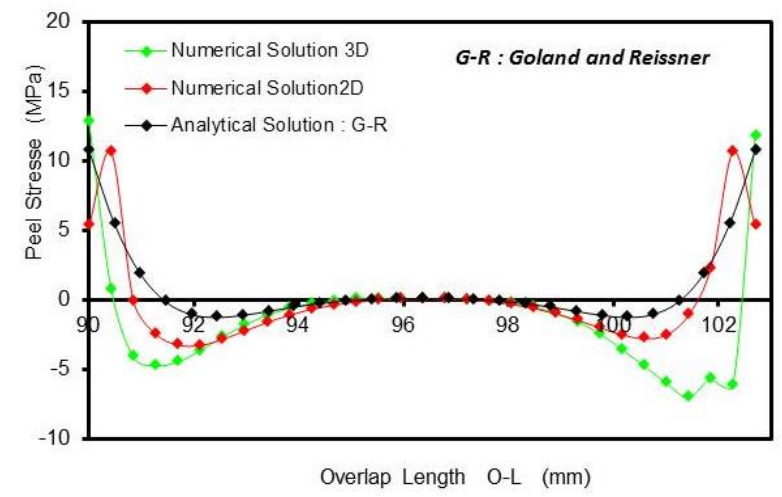

Fig. 6 Distribution of the adhesive peel stress along the overlap length

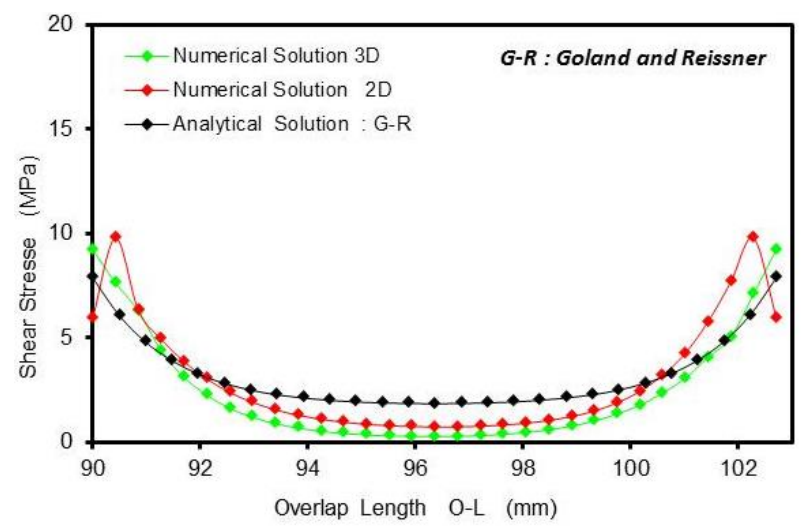

Fig. 7 Distribution of the adhesive shear stress along the overlap length 
These results were confirmed by the analysis of peel and shear stresses on the overlap length $(O-L)$ in the adhesive presented in Figs. 6 and 7 respectively; along the adhesive-adherend interface $(O-L)$, these stress components are highly non-symmetric. These figures show that, the stress field along the bond line (overlap length: $O-L$ ) is rather uniform away from the junctions (corners).

The stresses increase across the overlap region as the ends of the bond line are approached. At the junctions where the highest order of singularity exists, both the peel and shear stresses exhibit a strong singular behaviour. These stresses (peel and shear stresses) reach a maximum value at a short distance from the end of the single lap joint. We also observe, on the one hand, there are two peaks of peel stresses (Fig. 6) at the extremities of the overlap length $(O$ $L$ ) which may cause disband at the interface between adhesive and adhered plates. At the same location on the overlap length a two peak of shear stresses (Fig. 7) are also present at the ends of the overlap length where the peel stress presents the maximum values. This change in the peel and shear stresses distribution along the overlap length may be responsible for disband between layers in the plates. These figures (Fig. 6 and Fig. 7) compares the values of peel and shear stresses along the overlap length given by the finite element method with those calculated from the analytical model of Goland and Reissner [3]. Globally, it can be seen a fairly good correlation between the values predicted by our finite element model (FEM) and the analytical model. This later establishes the confidence in the results of the finite element modelling for bonded assemblies.

\subsection{Loading effect}

In this section, we have studied the influence of the loading amplitude on the distribution of the peel and shear stresses along the overlap length for bonded assemblies. A first observation from the reading of Fig. 8 is that the level of loading affects significantly on the peel stress distribution along the overlap length. We note also, that the increasing of loading level leads to decreasing of the shear stress values (Fig. 9) at the middle of overlap area, but the peel stress is higher in this position (i.e. distribution of peel stress is higher at the middle of overlap length for lower value of loading). This variable behaviour may be explained on the basis of changes in the loading level.

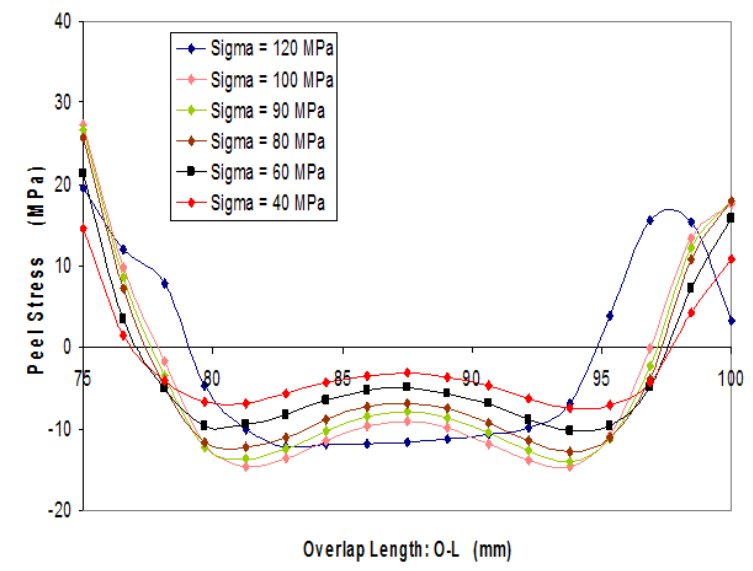

Fig. 8 Distribution of the adhesive peel stress along the overlap length for various loading condition and $O-L=25 \mathrm{~mm}$

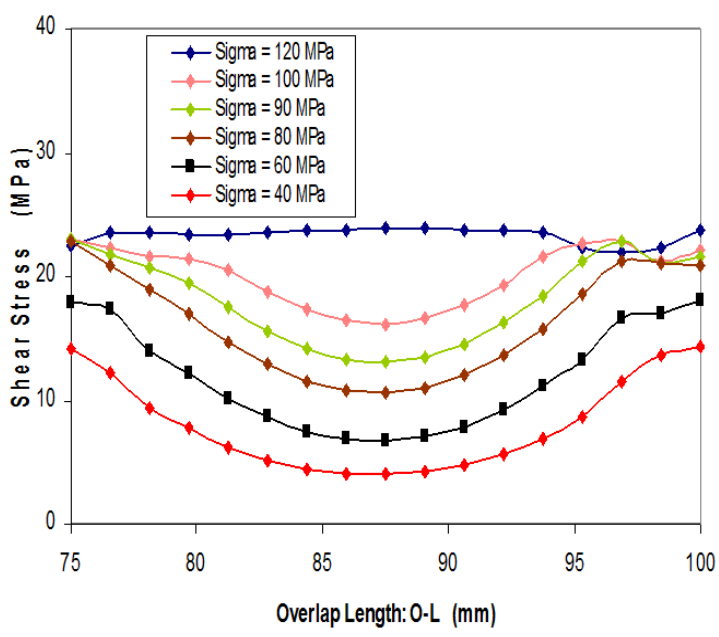

Fig. 9 Distribution of the adhesive shear stress along the overlap length for various loading condition and $O-L=25 \mathrm{~mm}$

One can deduce that, the level of load is responsible of failure mode of bonded assemblies. It can be conclude that the structure is subjected to a combination of tensile and bending loads. The bending component is caused by the eccentricity of the loads transmitted between the two plates. This bending phenomenon is responsible for stress concentrations at the free edge of overlap area, where the tensile and bending stresses add each other at the middle of overlap area. In other words, the increasing of load leads to an increasing of the bending phenomenon (peels stress higher; see Fig. 8) and to reduce the shear stress at the overlap length of bonded assembly (see Fig. 9). The interaction of these two factors (peel and shear stresses) which control the failure modes of single lap joint (i.e., cohesive, adhesive or mixed failure modes).

\subsection{Overlap length effect}

To determine the overlap length effect on the values of peel and shear stresses for single lap joint under tension solicitation, height values of this parameter $O-L=15$, 20, 25, 30, 35, 40, 45 and $50 \mathrm{~mm}$. have been investigated under loading $\sigma=60 \mathrm{MPa}$. Figs. 10 and 11 presents the evolution of peel and shear stresses along the overlap length for various overlap area $(O-L)$. The analyses of these figures show that the overlap length $(O-L)$ affects significantly on the values of peel stress. Indeed, the values of peel stress (Fig. 10) are higher in single lap joint with small overlap area $(O-L=15 \mathrm{~mm})$ as compared to higher overlap area $(O$ $L=50 \mathrm{~mm}$ ). In other words, the normal stress (peel stress) is zero values at the middle of $(O-L)$ and is negative values at the free edge of $(O-L)$ for higher overlap area (i. e. $O$ $L=50 \mathrm{~mm}$ ). This phenomenon can be explained by the fact that the adhesive is under complex loading (tension and compression) along the overlap area $(O-L)$. We find that the intensity of the stress field in free edge of $(O-L)$ is higher and therefore the failure mode is governed by the normal stresses (i. e. bending effect at the free edge of overlap area). We notice also that, independently of the overlap area $(O$ $L$ ), a decreasing of $O-L$ parameter leads to a decreasing of the amplitude value of shear stress (Fig. 11) and a increasing of the amplitude value of peel stress (Fig. 10). The comparative examination of the amplitude of peel and shear stresses 
along the overlap area for this loading condition, allows us to say that for the $O-L$ parameter lower the fracture behaviour of single lap joint is governed by the bending moment (amplitude of peel stress higher, see Fig. 10) and for the same condition of loading the shear mode on plane become dominate if the $O-L$ parameter is higher (amplitude of shear stress higher, see Fig. 11).

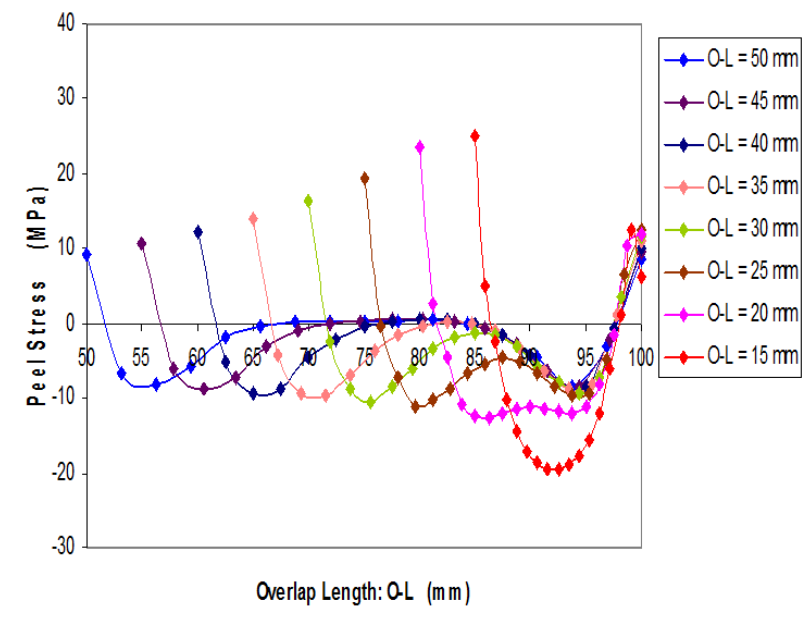

Fig. 10 Distribution of the adhesive peel stress along the overlap length for various $O-L$ parameter and $\sigma=60 \mathrm{MPa}$

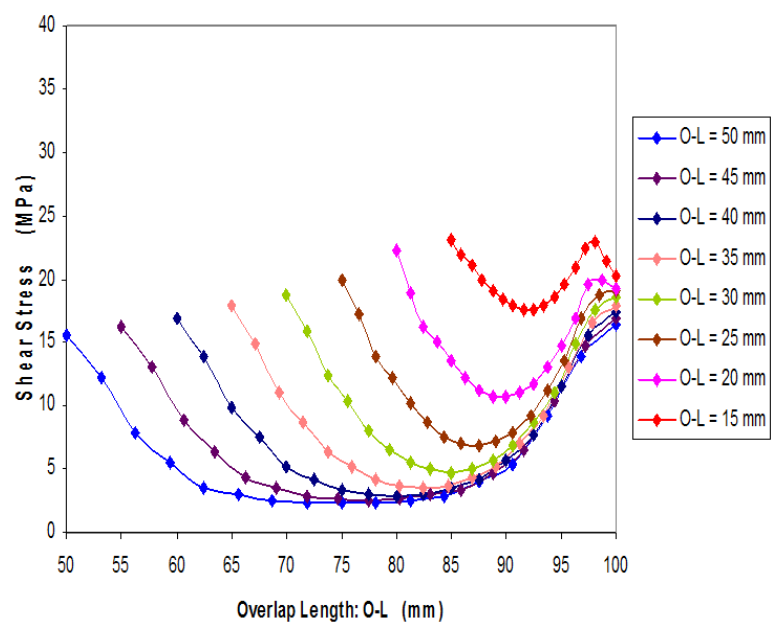

Fig. 11 Distribution of the adhesive shear stress along the overlap length for various O-L parameter and $\sigma=60 \mathrm{MPa}$

\subsection{Mixed-mode energy release rate}

Figs. 12-13 display the evolution of energy release rate (GI and $G I I)$ as a function of crack length. According to these figures, it can be observed that the energy release rate decreases with increasing of crack size. This behavior can be explained by the fact that the increase of crack (length of crack) leads a decreasing of energy at the vicinity of the crack which leads to the nucleation and risk of crack propagation. According to these results, it can be seen in present work, that the energy release rate (GI and GII) is logarithmic forms with the development of crack length.

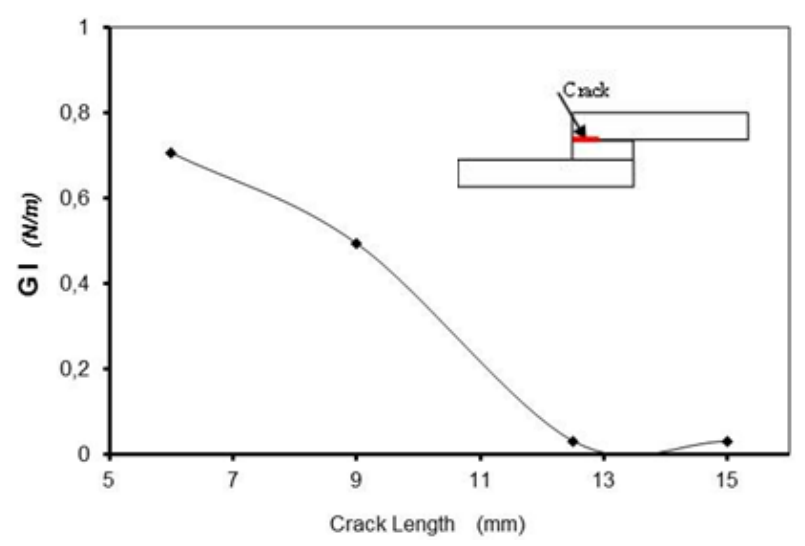

Fig. 12 Energy release rate $\left(G_{I}\right)$ versus crack length for $\sigma=80 \mathrm{MPa}$ and $O-L=25 \mathrm{~mm}$

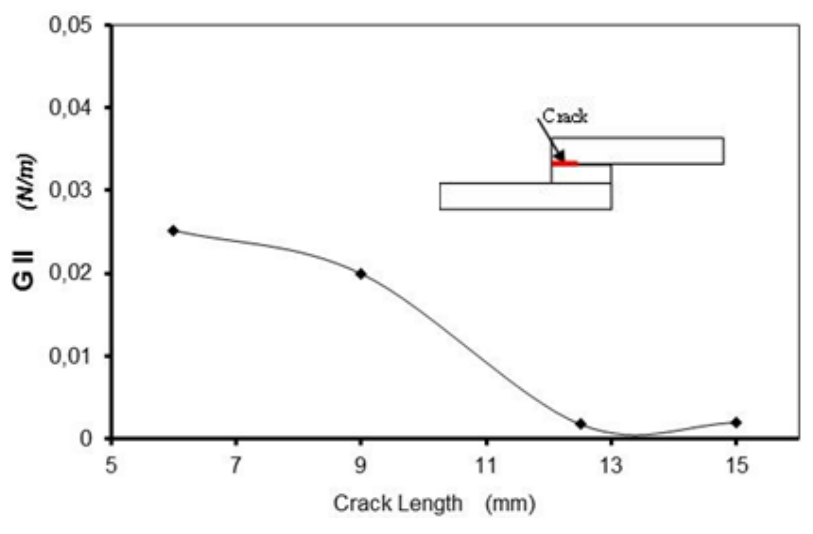

Fig. 13 Energy release rate $\left(G_{I I}\right)$ versus crack length for $\sigma=80 \mathrm{MPa}$ and $O-L=25 \mathrm{~mm}$

\section{Conclusions}

This study was carried out in order to analyse the interfacial adhesive stress distribution in the single lap joint under tensile loading. The obtained results allow us to deduce the following conclusions:

1. The developed a nonlinear finite element modelling approach to simulate the single-lap adhesive joints subjected to static tensile loading establishes the confidence in the results for bonded assemblies.

2. Good correlation was found between the FEM simulations and the analytical results.

3. The size of the overlap area is related at the magnitude of peel and shear stresses.

4. The magnitude of loading determines the mode failure of bonded assemblies (i.e., cohesive, adhesive or mixed failure modes).

5. The overlap area affects significantly on the values of peel and shear stresses and cause a secondary bending for single lap joint.

\section{References}

1. Benhamena, A.; Talha, A; Benseddiq, N.; Amrouche, A.; Mesmacque, G. and Benguediab, M. 2010. Effect of clamping force on fretting fatigue behaviour of bolted assemblies: Case of couple steel-aluminium, Materials Science and Engineering A 527: 6413-6421. http://dx.doi.org/10.1016/j.msea.2010.06.080.

2. Benhamena, A.; Amrouche, A.; Talha, A; 
Benseddiq, N. 2012. Effect of contact forces on fretting fatigue behaviour of bolted plates: Numerical and experimental analysis, Tribology International 48: 237-245. http://dx.doi.org/10.1016/j.triboint.2011.12.008.

3. Goland, M.; Reissner, E. 1944. The stresses in cemented joints, Trans. ASME, Journal of Applied Mechanics 11: A17-A27.

4. Panigrahi, S.K.; Pradhan, B. 2007. Three dimensional failure analysis and damage propagation behavior of adhesively bonded single lap joints in laminated, J Reinf Plast Compos 26: 183-201. http://dx.doi.org/ 10.1177/0731684407070026.

5. Sheppard, A.; Kelly, D.; Tong, L. 1998. A damage zone model for the failure analysis of adhesively bonded joints, Int J Adhes Adhes 18: 385-400. http://dx.doi.org/10.1016/S0143-7496(98)00024-4.

6. Chen, D.; Cheng, S. 1998. An analysis of adhesivebonded single-lap joints, Journal of Applied Mechanics 50: 109-115. http://dx.doi.org/ 10.1115/1.3166976.

7. Oplinger, D.W. 1994. Effects of adherend deflections in single lap joints, Int J Solids Struct 3: 2565-2587. http://dx.doi.org.www.sndl1.arn.dz/10.1016/00207683(94)90037-X.

8. Tsai, M.Y.; Oplinger, D.W.; Morton, J. 1998. Improved theoretical solutions for adhesive lap joints, International Journal Solids Structures 35: 1163-1185. http://dx.doi.org/10.1016/S0020-7683(97)00097-8.

9. Allman, D.J. 1977. A theory for elastic stresses in adhesive bonded lap joints, Quarterly Journal of Mechanics and Applied Mathematics 30: 415-436. http://dx.doi.org/10.1093/qjmam/30.4.415.

10. Aydin, M.D.; Özel, A.; Temiz, S. 2005. The effect of adherend thickness on the failure of adhesively-bonded single-lap joints, J Adhes Sci Technol 19: 705-718. http://dx.doi.org/10.1163/1568561054890499.

11. Reis, P.; Antunes, F. 2005. Influence of superposition length on mechanical resistance of single-lap adhesive joints, Compos Struct 67: 125-133.

http://dx.doi.org/10.1016/j.compstruct.2004.01.018.

12. Bresson, G.; Jumel, J.; Shanahan, M.E.R. Serin, P.
2013. Statistical aspects of the mechanical behaviour a paste adhesive, International Journal of Adhesion \& Adhesives 40: 70-79.

http://dx.doi.org/10.1016/j.ijadhadh.2012.06.006.

13. ANSYS v11.0, Ansys Inc. Documentation, ANSYS Elements Reference.

14. Cheuk, P.T.; Tong, L.; Wang, C.H.; Baker, A.; Chalkley, P. 2002. Fatigue crack growth in adhesively bonded composite-metal double-lap joints, Compos Struct 57: 109-115.

http://dx.doi.org/10.1016/S0263-8223(02)00074-0.

A. Djebli, A. Benhamena, L. Aminallah, A. Aid, M. Benguediab, A. Amrouche

\section{THREE-DIMENSIONAL FINITE ELEMENT ANALYSIS OF FRACTURE BEHAVIOUR OF ADHESIVELY BONDED SINGLE LAP-JOINTS}

S u m m a r y

The goal of this work is to analyze the severity of interfacial stress distribution in the single lap adhesive joint under tensile loading. The non-linear finite element method based on the computation of the peel and shear stresses was used to analyze the fracture behavior of single lap adhesive joint. The effect of the loading magnitude and the overlap length on the distribution of peel and shear stresses was highlighted. A good correlation was found between the FEM simulations and the analytical results.

Keywords: Aluminum 2024-T3 alloy, Single-lap adhesive joints, Interface stress distributions, Material nonlinear analysis, Adhesive, Bending moment, Finite element method.

Received August 14, 2015 Accepted September 28, 2016 